\title{
Corrosion and Protection of the Condenser Seawater Cooling System
}

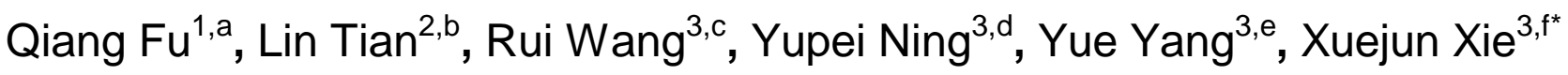 \\ ${ }^{1}$ Guangdong Power Grid Electric Power Science \& Research Institute, Guangzhou, China \\ ${ }^{2}$ Cnooc zhuhai gas power generation co., LTD, China \\ ${ }^{3}$ School of Power and mechanical engineering, WuhanUniversity, Wuhan, China \\ a13926402226@163.com, barlyne-tian@qq.com, c1193944478@qq.com,d \\ 2529942777@qq.com, ${ }^{e} 405957803 @ q q . c o m,{ }^{\dagger}$ xiexuejun@163.com
}

\section{${ }^{*}$ Correspondent}

Keywords: Seawater; Cycling cooling; Disadvantage.

Abstract. Composition and main material of seawater cooling systems of power units are stated briefly. Some corrosion and protection examples of seawater cooling systems are summaried. In order to protect overall seawater cooling system, the suitable material should be chosen firstly, and surface treatment such as coating or lining and cathodic protection should be done well secondly. In order to protect seawater cycling cooling system, beyond that, protection of the seawater cycling cooling tower and biocide treatment of the seawater cycling cooling system should be done well, too. In addition, rubber ball cleaning should be done well, the seawater cycling cooling system, especially the inner surface of condenser pipes should be kept clean.

\section{The composition of seawater cooling system}

Cooling ways include once-through cooling and cycling cooling when water is used as industrial cooling water.

Once-through cooling using seawater is that seawater is discharged directly after it is pumped through simple grid filters and into the condensers or other heat exchange equipment. The cooling system consists of pipes (including straight pipes, elbow pipes and pipe reducers, etc), equipment (such as condenser, heat exchanger, grid filter, butterfly valve, etc).

Cycling cooling using seawater is that seawater is recycled through cooling towers after it is pumped through simple grid filters and into condensers or other heat exchange equipmen. The obvious difference on the composition is cycling cooling system with and once-through cooling system without a cooling tower. ${ }^{[1-3]}$

For example, the cooling water of a coastal power plant with $300 \mathrm{MW}$ units is natural seawater. The cooling water system includes a $32 \mathrm{~m}$ Q235A steel pipe with $\Phi$ (outside diameter of) $1820 \mathrm{~mm} *$ (thickness of) $16 \mathrm{~mm}$ in the main building, 4 Q235A elbow pipes with $90^{\circ}$ bend and $\Phi 1820 \mathrm{~mm}, 4$ Q235A butterfly valves and expansion pipes with DN (nominal diameter) $1800 \mathrm{~mm}, 2$ secondary 316L filter nets with DN $1800 \mathrm{~mm}, 2$ ball recovery nets, whose shell is made of carbon steel lining plastic and other main material is $317 \mathrm{LN}$ stainless steel, 4 ripple compensators with DN $1800 \mathrm{~mm}$, whose main material is stainless steel, the condenser, whose water chamber is rubber lining, pipe material is titanium, and pipe sheet is steel clad plate of titanium. The cooling water system also includes a $66 \mathrm{~m}$ Q235A steel pipe with $\Phi 820 \mathrm{~mm}^{*} 7 \mathrm{~mm}, 2$ electric water filters with whole material of 316L stainless steel, a 7m Q235A steel pipe with $\Phi 630 \mathrm{~mm} * 7 \mathrm{~mm}$, a $6 \mathrm{~m} \mathrm{10CrMoAl} \mathrm{steel} \mathrm{pipe} \mathrm{with} \Phi 529 \mathrm{~mm} * 7$ $\mathrm{mm}, 2$ closed-cycle heat exchangers, whose material is titanium, a $75 \mathrm{~m} 10 \mathrm{CrMoAl}$ steel pipe with $\Phi 377 \mathrm{~mm} * 7 \mathrm{~mm}, 9$ electric butterfly valves, 6 hot-pressed elbows with $90^{\circ}$ bend and DN $800 \mathrm{~mm}, 4$ hot-pressed elbows with DN $600 \mathrm{~mm}, 2$ hot-pressed elbows with DN $500 \mathrm{~mm}, 2$ transition pipes with $800 \mathrm{~mm} ? 500 \mathrm{~mm}, 8$ transition pipes with $600 \mathrm{~mm} ? 500 \mathrm{~mm}, 4$ transition pipes with $\Phi 500 \mathrm{~mm} * 350$ $\mathrm{mm}$, a $45 \mathrm{~m}$ steel pipe with $\Phi 325 \mathrm{~mm} * 6 \mathrm{~mm}$, a $48 \mathrm{~m}$ steel pipe with $\Phi 219 \mathrm{~mm} * 6 \mathrm{~mm}, 8$ valves with different types, 1 electric water filter, 2 oil coolers, and some bends and transition pipes. ${ }^{[4]}$ 
The condensers of $2 * 1000 \mathrm{MW}$ units of the second stage of the project of Zhejiang Guohua Ninghai power plant are cooled by the cycling seawater with 2 hyperbolic natural draft reinforced concrete cooling towers. The cooling tower consists of air funnel, truss-column, ring type foundation, pool, Water spray architecture, cenote, etc, with the water drenching area of $13000 \mathrm{~m}^{2}$, the height of $177.20 \mathrm{~m}$, the outlet radius of $39.66 \mathrm{~m}$, the shell max thickness of $1.40 \mathrm{~m}$, the shell min thickness of $0.28 \mathrm{~m}$, the shell internal surface area of $50004 \mathrm{~m}^{2}$, the shell surface area of $50361 \mathrm{~m}^{2} .{ }^{[5]}$

Therefore, the main material of the seawater cooling system is carbon steel (such as Q235A, $10 \mathrm{CrMoAl}$ ), stainless steel (such as $316 \mathrm{~L}$ and $317 \mathrm{LN}$ ), titanium material (such as TA0, TA1 and TA2) or titanium-steel composite sheet, in addition, the material of the seawater cycling cooling system of the cooling tower is reinforced concrete. There is a lot of equipment made of carbon steel in seawater cooling system, such as water pipe, valve, filter shell, heat exchanger water chamber, etc. They are widely made of carbon steel lining rubber, plastic, or cement mortar, and carbon steel with heavy anticorrosive coating.

In China, stainless steel is mainly used in the first and second filter devices in the seawater cooling system, while titanium is mainly used in the condenser pipe bundle, pipe sheet. Especially in recent years, since the water pollution is becoming more and more serious, it should be considered in the power plant where the seawater is used as the cooling water. Titanium is a very good choice to prevent corrosion, so it is made into condenser pipes of all new coastal power plants in our country.

Besides titanium pipes, super ferritic stainless steel pipe is also in large-scale adapted to condensers cooled by the seawater abroad. In the United States, it is believed that the stainless steel adapted to seawater includes AL6XN, 254 SMO, AL29 - 4C and SEA - CURE, super stainless steel, especially super ferritic stainless steel is an excellent choice to replace titanium, because the demand of titanium in the aerospace and other fields is big, and to save the titanium resource is of great economic significance.

AL6XN is super austenitic stainless steel, and is adapted to condensers of power plants in the United States early. But the mass fraction of nickel is high (above 23.5\%), the price of nickel is very high in recent years. Therefore, AL6XN's price is even higher than titanium, therefore, AL6XN pipes are seldom used in power plant condensers. AL29 - 4C and SEA - CURE are super austenitic stainless steel, whose characterics is low mass fraction of $\mathrm{Ni}$ (less than 3.5\%) and high mass fraction of $\mathrm{Cr}$ (above 25\%), and their price is low. Therefore, they are suitable to be adapted for a wide range. But the requirement of their manufacture technology is high, for example, mass fraction of $\mathrm{C}$ or $\mathrm{N}$ is required to be less than $0.06 \%$, and the requirement of manufacturing pipe is also high. In fact, the SEA - CURE pipe has been adapted to condensers of coastal power plants for a large range, while about the application of AL29-4C, there is only an failure case that the leakage of the condenser pipe made of AL29 - 4C in a power plant happened in the United States, and the AL29 - 4C pipes are replaced by SEA - CURE pipes. ${ }^{[6,7]}$

\section{Corrosion protection principle and methods of the seawater cooling system}

Corrosion protection principle of the seawater cooling system. Since the $\mathrm{O}_{2}$ content dissolved in the seawater is enough and nearly saturation in the seawater cooling process, and the metal surface is of heterogeneity and the seawater has the strong electrical conductivity, many corrosion microcell are formed on the metal surface. But not all metal corrodes in the seawater, especially some metal with a protective film formed on the surface, such as titanium doesn't corrode even it is in the seawater due to a good protective film formed on the titanium surface. Therefore the metal with good corrosion resistance in the seawater can be chosen to prevent the condenser pipes and the pipe plates in the seawater cooling system from corrosion. Because the metal corrosion in the seawater is mainly electrochemical corrosion, and it occurs only when the metal directly contacts with the seawater, surface treatment, such as coating and lining to isolate the metal and the seawater, and the sacrificial anode and impressed current cathodic protection can prevent the seawater cooling system from corrosion. If the surface of the metal in the seawater isn't clean, such as sediment, the metal corrosion 
is prone to occur under the sediment, and the rubber ball cleaning and the killing processing, etc should be done well to keep the metal surface clean and prevent corrosion.

Corrosion protection methods of the seawater cooling system. According to the corrosion protection principle, the corrosion protection methods of the seawater cooling system includes choosing the suitable material, such as titanium that is chosen to make the condenser pipes and the pipe sheets in the seawater cooling system in our country at present, and doing well the surface treatment such as coating or lining and cathodic protection.

In order to protect the seawater cycling cooling system, beyond all above, the protection of the seawater cycling cooling tower and the biocide treatment of the seawater cycling cooling system should be done well, too. In addition, the rubber ball cleaning should be done well, the seawater cycling cooling system, especially the inner surface of condenser pipes should be kept clean.

To choose suitable material for the seawater cooling system. Titanium is chosen to make condenser pipes of the seawater cooling system, since its specific intensity is high and its density is small, it has good comprehensive performance and best corrosion resistance, such as resistance to corrosion of the seawater and the polluted seawater, erosion corrosion of the high speed seawater, and ammonia corrosion of the condenser air removal section. But biological fouling problems appear easily, and should be emphasized and solved.

The characteristic of the thin-wall titanium welding pipe is as follows. The pipe surface is smooth, bright, the weld inside and outside of the pipe is smooth and uniform transition, wall thickness is uniform, elastic modulus is low, heat transfer effect is good, and the total heat transfer performance is above 5\% higher than that of brass. Because the titanium welding pipe wall is thin, the number of support sheets should increase to reduce mutual friction and collision between pipe and pipe, pipe and support sheet hole, and to prevent violent vibration caused by the airflow and pipe wall from local thining and cracking. Because Titanium's corrosion resistance is good, the pipe's service life is long, such as above 20 years, and the operation and maintenance cost is low. ${ }^{[8,9]}$

Practice has proved that titanium welded pipe has become an ideal material of condenser pipes in the cooling seawater with bad quality in the coastal area, and is the favour of the power industry material experts, the power plant operation and management personnels. ${ }^{[10]}$

Comparing with the traditional cast iron pipe, steel pipe, cement pipe, plastic pipe's advantages are smooth inner wall, small resistance, good sealing and corrosion resistance, convenient connection, etc, its shortcomings are bad compression resistance, low strength, high requirement for laying environment, poor resistance to impact, part of the pipe material aged easily, etc.

To do surface treatment such as coating or lining and cathodic protection well. Cathodic protection technology includes the sacrificial anode and the impressed current. The two methods have their own advantages and disadvantages. In the power plant seawater cooling system, that which method is concretely adopted is often determined by the size of the needed protection electric current, if the input power supply can be obtained conveniently, if dangers will be caused and the size of equipment structure.

The impressed current cathodic protection is used more appropriately in the case that large protection current need to be offered because of small-bore pipe, velocity and medium composition with great variation. In recent years, the impressed current cathodic protection is adopted more and more in the power plant seawater cooling system. For example, in order to prevent the seawater cycling cooling system of a 900MW supercritical unit in Waigaoqiao power plant from electrochemical corrosion, the impressed current cathodic protection is adopted to protect the condenser water tank, the cooling water pipes, the trash rack, the steel gate, in and out of the water pipe of the cycling pump, the surface of the cycling water pipe, and its protection effect is good. ${ }^{[11]}$

The cooling water of a coastal power plant with $300 \mathrm{MW}$ units is natural seawater. The seawater cooling system is all protected by the impressed current cathodic protection, and the protection is effective. The cooling water of another coastal power plant with $300 \mathrm{MW}$ units is natural seawater, too. The protection system consists of the auxiliary anode, reference electrode, the potentiostat, anode screen and connection cable etc. Platinum niobium and the mixed metal oxide (MMO) are chosen as 
auxiliary anode, $\mathrm{Ag} / \mathrm{AgCl}$ and high purity zinc composite reference electrode is chosen as the system control and detection electrode. ${ }^{[4]}$

The cathodic protection is an effective method to prevent or slow down the corrosion. The united protection of cathodic protection and surface treatment such as lining or coating is often adopted, such as the carbon steel material of the seawater cycling system of the secondary circuit of Qinshan nuclear power plant is often protected by the united protection of cathodic protection and coating. ${ }^{[12,13]}$

In the cathodic protection design and implementation, the choice of the protection current density and how to make the protection current distribution uniform is very critical. When the device with electric connection with titanium is implemented the cathodic protection, the hydrogen embrittlement of titanium should be prevented. ${ }^{[14,15]}$

Anticorrosion of the seawater circulating cooling tower. Anticorrosion coating is mainly adopted in the seawater circulating cooling tower. The overall bonding strength of coating and concrete must be kept greatly to improve the sealing properties of the coating on the concrete. The coating thickness and uniformity is demanded strictly. Top paint sprayed is smooth, no flow, no pores, no pinhole, no obvious interval mark, no crack and no flake, and the surface is smooth, transparent and beautiful. ${ }^{[5,15]}$

\section{Conclusions}

(1) The seawater cooling system consists of pipes (including straight pipes, elbow pipes and pipe reducers, etc), equipment (such as condenser, heat exchanger, grid filter, butterfly valve, etc.), besides all above, there is a cooling tower in the seawater cycling cooling system. The main material of the seawater cooling system is carbon steel (such as Q235A, $10 \mathrm{CrMoAl}$ ), stainless steel (such as 316L and $317 \mathrm{LN}$ ), titanium material (such as TA0, TA1 and TA2) or titanium-steel composite sheet, and reinforced concrete.

(2) In order to protect overall seawater cooling system, the suitable material should be chosen firstly, the surface treatment such as coating or lining and the cathodic protection should be done well secondly. In order to protect the seawater cycling cooling system, beyond that, the protection of the seawater cycling cooling tower and the biocide treatment of the seawater cycling cooling system should be done well, too. In addition, the rubber ball cleaning should be done well, the seawater cycling cooling system, especially the inner surface of condenser pipes should be kept clean.

\section{References}

[1] Yuzhong Zhang, Xiaomin Peng, Industrial water treatment, 24 (8) (2004) 14 - 17.

[2] Ming Xu, Electric power construction, 23 (5) (2002) 12 - 13.

[3] Chunyan Yang, Yongzhang Zhou, Min Liu, Kaiwei Guo, Corrosion \& protection, 32 (7) (2011) $532-534,561$.

[4] Zheng Qu, Qiwei Pang, Chao Meng, Total corrosion control, 18 (4) (2004) 14 - 17.

[5] Chengjiang Sun, Liang Han, Engineering Journal of Wuhan University, 42 (2009) 482 - 486.

[6] Feng Xu, Huadian technology, 31 (6) (2009) 39 - 42.

[7] Changchun Wang, Chengming Wang, Wenyuan Zhen, Electric Safety Technology, 11 (2) (2009) $18-21$.

[8] Yongchun Fan, Thermal power generation, 2 (2007) 81 - 83, 86.

[9] Yongchun Fan, Electric power survey \& design, 4 (2006) 69 - 72.

[10] Pengfei Sun, Metal World, 4 (2000) 31

[11] Zhimin Zhou, Shanghai electric power, 4 (2004) 306 - 308. 
[12] Hongtao Lu, Honglian Zheng, Guodong Yang, China nuclear power, 3 (1) (2010) 64 - 69.

[13] Jinghai Liu, Guangshen Zhan, Qiao Peng, Zhengan Yin, Electric power, 33 (12) (2000) 21 - 24.

[14] Xiuying Liu, Northeast electric power technology, 5 (2004) 31 - 32, 36.

[15] Chunyang Hou, Jie Wu, Nan Zhao, Yunfang Wu, Shujing Liu, Weizhen Wang, Ocean technology, 21 (4) (2002) 46 - 50. 